\title{
Hepatitis B Virus Subtype Distribution in Bangladeshi Chronic Carriers
}

\author{
B Tanzem ${ }^{1}$, S Tabassum² ${ }^{2}$ S U Munshi ${ }^{3}$, M Jahan ${ }^{4}$
}

\begin{abstract}
Background : Hepatitis B virus (HBV) infection is one of the major global health problems and this virus has many variants that differ from epidemiological distributions, transmission sources, clinical outcomes, diagnostic assays as well as therapeutic responses. HBV was also divided into 9 different subtypes which has distinct geographical distributions and important for the epidemiological studies and vaccine development.

Objective : Bangladesh is an intermediate prevalence region for HBV infection, however, very little is known about the incidence of HBV subtypes in circulation. Therefore, we investigated the HBV subtype distribution in Bangladesh.

Method : A small cohort was performed on between March 2014 and August 2017 with 172 HBV DNA positive patients from the BSMMU. From them, $29 \mathrm{HBV}$ DNA samples were isolated for sequencing by Sanger method. $\mathrm{HBsAg}$ subtypes were determined by identifying of 226 amino acid (aa) positions in the small surface (S) gene.

Result : Our study showed that HBV subtype adrq + was in $17(58.6 \%)$ isolates, ayw3 in 8 (27.5\%), ayw2 in 2 (6.9\%) and adw2 in $2(6.9 \%)$ isolates.

Conclusion : We conclude subtype adrq + predominant in Bangladesh. This was followed by ayw3, while adw2 and ayw2 were least dominant. Subtype adw2 and adrq + strains are found to be related with more complication, therefore, patients infected with these HBV strains need to be careful monitoring to assess their clinical outcome in future.
\end{abstract}

Key words : HBV, subtype, clinical complications.

DOI: http://dx.doi.org/10.3329/nimcj.v9i2.38908

Northern International Medical College Journal Vol. 9 No. 2 January 2018, Page 286-290

\section{Dr. Bushra Tanzem Assistant Professor Dept. of Microbiology Northern International Medical College, Dhanmondi, Dhaka.}

${ }^{2}$ Professor Shahina Tabassum Chairman Dept. of Virology, BSMMU

3 Professor Saif Ullah Munshi Professor Dept. of Virology, BSMMU

${ }^{4}$ Dr. Munira Jahan Associate Professor Dept. of Virology, BSMMU

Correspondence Dr. Bushra Tanzem Assistant Professor Dept. of Microbiology Northern International Medical College e-mail: tanzeembushra@gmail.com double-stranded DNA genome of nearly 3200 base pair (bp) lengths that arranged in four overlapping open reading frames (ORFs), such as, polymerase ( $\mathrm{Pol}$ ) gene, envelop/surface (S) gene, core/precore (C/PC) gene and X ORFs gene. Many HBV genotypes, subtypes, different HBV genomic mutants and recombinants emerge over time due to the presence of reverse transcriptase (RT) enzyme which does not have any proof reading ability. In addition, external selection pressure by antiviral agents and vaccine causes many viral variants. Till date, HBV classified into 10 genotypes named as A to J and also 40 subgenotypes. ${ }^{9,10}$ These 10 genotypes have nucleotide differences more than $7.5 \% .{ }^{11}$ Whereas, "Sub genotypes" are subgroups within the same genotype that contains nucleotide difference as $4 \%$ to $7.5 \% .^{12}$ "Clades" are further division of sub genotypes based on less than $4 \%$ nucleotide differences. ${ }^{11}$

Before the definition of genotypes, HBV were classified as serotypes (subtypes) according to 
serological differences, based on immune reaction by amino acid pattern at specific location of "a" determinant which leads to the 9 different subtypes designating adw2, adw4, adrq+, adrq-, ayw1, ayw2, ayw3, ayw4 and ayr. ${ }^{13}$ Subtypes correlate broadly with genotypes. Some subtype can be found in more than one genotype, which confer additional heterogeneity within the genotypes. Subtypes are important for the epidemiological studies and vaccine development.

Therefore, the determination of HBV subtypes will be helpful in epidemiological surveillance as well as development of the appropriate vaccine in Bangladesh. This will help to control of $\mathrm{HBV}$ infection in Bangladesh in near future.

At present, the $\mathrm{HBsAg}$ used in all vaccines contains the adw subtype of HBsAg. Whether this vaccine is appropriate for our population or not our is unknown as limited data available regarding the HBV subtypes in Bangladesh. Therefore, our study focused to determine the HBV subtype distribution in Bangladesh.

\section{Materials and Methods}

\section{Patients}

This small cohort was done on between March 2014 and August 2017 with chronic hepatitis B patients at the department of Virology, BSMMU, Dhaka, Bangladesh. The selection criteria were

- more than 6 months HBsAg positivity along with HBV DNA positive which was detected by real-time PCR.

A total of 172 patients were interviewed with a pretested questioner at BSMMU. From them, only 29 patients were selected for molecular study from March 2014 to December 2014. Then the patients were yearly once followed upto August 2017.

Blood samples were collected from these 29 selected patients in a microcentrifuge tube containing anti-coagulant EDTA 5\%.Then plasma was separated from centrifugation of blood. The separated plasma was aliquot in a centrifuge tube and kept at $20^{\circ} \mathrm{C}$ until testing.

The study was ethically approved by the Institutional Review Board of Bangabandhu Sheikh Mujib Medical University, Dhaka, Bangladesh and written informed consent for participating in this study was obtained from all patients.

\section{Isolation of HBV DNA}

Extraction of HBV DNA was done from $200 \mu$ l of plasma using DNeasy Blood and Tissue Kit (QIAGEN, Venlo, Limburg, The
Netherlands) according to manufacturer's instruction. Extracted DNA was stored at -20 until PCR.

\section{Amplification of viral DNA}

HBV DNA was amplified using nested PCR that targeted a 1014bp region of the $S$ gene. Amplification was performed using the following primers: 3079-3099 (5'-AGC CCT CAG GCT CAG GGC ATA-3') / 1163-1140 (5'- CGT TGC CKD GCA ACS GGG TAAAGG$\left.3^{\prime}\right)$ as external primers and 3192-3211 (5'-TCA TCC TCA GGC CAT GCA GT-3') / 991-972(5'-GAC ACA CTT TCC AAT CAA TNG G-3') as internal primers (Biobasic, Canada), as described previously ${ }^{14}$. After both reactions, a 1014-bp fragment was obtained and detected by ethidium bromide staining in an agarose gel.

\section{DNA purification and sequencing}

Exonuclease Clean-up of nested PCR Products were done by ExoSAP-IT (USB Corp, Cambridge), according to manufacturer's instructions. For cycle sequencing reactions, internal PCR primers and a BigDye $₫$ Terminator v3.1 Cycle Sequencing Kit (California) were used. The product of cycle sequencing was purified by BigDye ${ }^{\circledR}$ XTerminator ${ }^{\mathrm{TM}}$ Purification Kit. Sequencing was carried out in an automatic sequencer (ABI PRISM $® 3500 \mathrm{xL}$ Genetic Analyzer).

\section{HBV DNA sequence analysis}

The electropherogram files of the all 29 obtained HBV DNA forward and reverse nucleotide sequences were examined and edited using Chromas 2.3 (Technelysium). The nucleotide sequences for sequence similarity searches were performed using the NCBI (National Institutes of Health, Bethesda, MD, USA) BLAST server on Gene Bank database. Sequences were aligned by using the Clustal $\mathrm{W}$ program located in the BioEdit 7.0.9.0 suite of programs. ${ }^{15}$ Finally, 226 aa of 678 nucleotide (nt) fragment in the HBV S gene (nt 155-835) of HBV were analyzed. Numbering was done according to BioEdit alignment with the NCBI Reference Sequence no: NC_003977.1.

\section{Phylogenetic analysis and HBV genotyping}

The HBV genotype was identified by phylogenetic tree analysis. The sequences from the present study were compared to GeneBank sequences in a BLAST search. The nucleotide sequences were aligned pair wise using Clustal W program. Phylogenic tree was constructed according to Neighbor-Joining method using MEGA 6.06 package. ${ }^{16}$ The bootstrap probability at each branching point was calculated with 500 pseudoreplicate data sets. ${ }^{17}$ Evolutionary distances in the phylogenetic tree were computed using the p-distance method and are in the units of 
the number of amino acid differences per site. ${ }^{18}$ All positions containing gaps and missing data were eliminated. There were a total of 226 amino acid positions in the final dataset. Genotyping was also done by using the three online genotyping tools. ${ }^{19,20,21}$

\section{Determination of HBV subtypes}

Determination of the HBsAg subtypes were done from the HBV DNA sequence of the $\mathrm{HBsAg}$ protein based on identifying amino acids positions at $122[\mathrm{Lys}(\mathrm{K}) / \operatorname{Arg}(\mathrm{R})$ for $\mathrm{d} / \mathrm{y}$ determinants], 160 $[\operatorname{Lys}(\mathrm{K}) / \operatorname{Arg}(\mathrm{R})$ for $\mathrm{w} / \mathrm{r}$ determinants], $127[\operatorname{Pro}(\mathrm{P}) / \operatorname{Thr}(\mathrm{T}) /$ Leu(L)-Ile(I) for w2/w3/w4], and in the case of $\operatorname{Arg}(\mathrm{R})$ at 122, $\operatorname{Pro}(\mathrm{P})$ at $127, \operatorname{Lys}(\mathrm{K})$ at 160 , also at positions $159[\mathrm{Ala}(\mathrm{A}) /$ not Ala (A) for ayw1/ayw2 and ayw4] and 140 [not $\operatorname{Ser}(\mathrm{S}) / \operatorname{Ser}(\mathrm{S})$ for ayw2/ayw4].22-23

\section{Statistical analysis}

Statistical analysis of data was performed using the SPSS software package 17.0 (IBM SPSS Statistics for Windows, the study population, $22(75.9 \%)$ patients were HBeAg positive and $7(24.1 \%)$ patients were HBeAg negative (Table-1).

Table 1 : Comparison of demographic and laboratory data of 29 study patients Demographic and laboratory data of total 29 study patients

\begin{tabular}{|c|c|}
\hline Study group, n (\%) & 29 \\
\hline Male, n (\%) & $25(86.2 \%)$ \\
\hline Female, $\mathrm{n}(\%)$ & $4(13.8 \%)$ \\
\hline Age in years, Mean \pm SD (Range) & $29.8 \pm 12(4-50)$ \\
\hline Serum ALT (U/I), Mean \pm SD (Range) & $89.8 \pm 74.9(15-4$ \\
\hline$* \mathrm{HBV}$ viral load (IU/ml), Mean $\pm \mathrm{SD}$ (Range) & $\begin{array}{l}5.5 \times 10^{7} \pm 1.5 \times 1 \\
\left(9.1 \times 10^{2}-7.0 \times 10\right.\end{array}$ \\
\hline \multicolumn{2}{|l|}{ Plasma HBeAg status, } \\
\hline Positive & $22(75.9 \%)$ \\
\hline Negative & $7(24.1 \%)$ \\
\hline
\end{tabular}

Note: *HBV viral load in plasma.

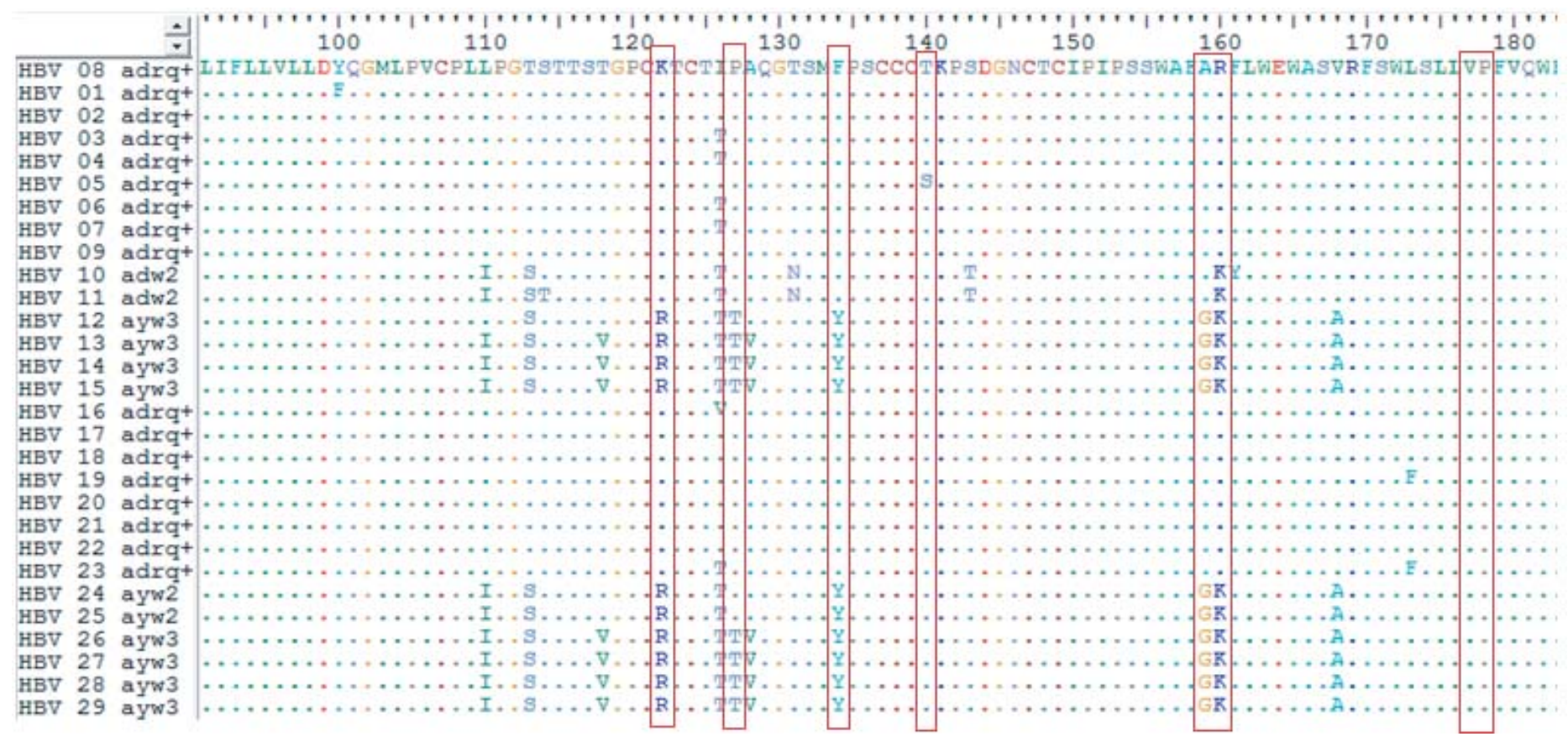

Figure 1: HBV subtype determination* Red boundaries in figures show amino acid positions that were analyzed.

Armonk, NY, USA).

\section{Results}

A total of 29 patients were selected for sequencing of HBV DNA and sequence analysis. Among them, 25 (86.2\%) patients were male and $4(13.8 \%)$ patients were female with a mean age of $29.8 \pm 12$ years and age range of 4 to 50 years. Their viral load values varied from $9.1 \times 10^{2}$ to $7.0 \times 10^{8} \mathrm{IU} / \mathrm{ml}$, with mean value of $5.5 \times 10^{7}\left(\mathrm{SD} \pm 1.5 \times 10^{8}\right) \mathrm{IU} / \mathrm{ml}$. ALT values varied from 15 to $419 \mathrm{U} / \mathrm{l}$, and mean ALT level was $89.8(\mathrm{SD} \pm 74.9) \mathrm{U} / \mathrm{l}$. Among acids alignment of the small $\mathrm{S}$ gene of HBV from our study results (Figure 1).

In this study, the observed frequency of HBV subtypes among study patients were adrq ${ }^{+}$in 17 (58.6\%) isolates, ayw 3 in 8 (27.5\%), ayw2 in $2(6.9 \%)$ and adw2 in 2 (6.9\%) isolates (Figure 2). In association of genotypes with subtypes, genotype C of HBV isolates showed all were adrq ${ }^{+}$subtype. Similarly, both genotypes $A$ isolates found adw2 subtype. Whereas, genotype $D$ showed two different subtypes: ayw3 in 8 (27.5\%) and ayw2 in $2(6.9 \%)$. 


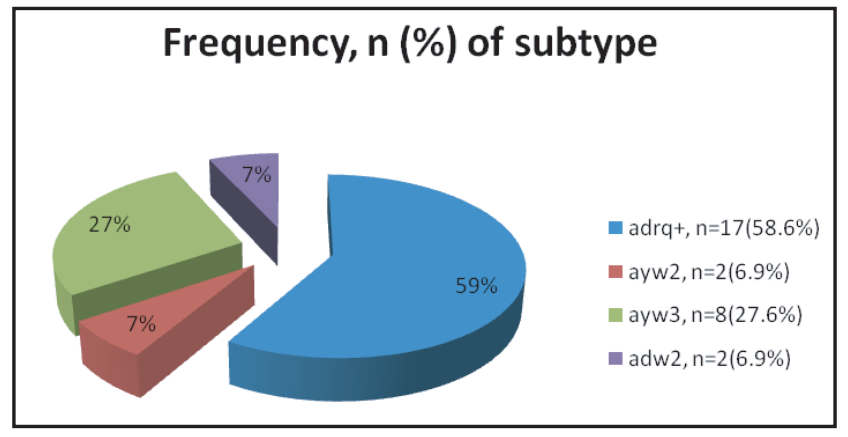

Figure 2 : Frequency of subtype, n(\%)

On observation of the study patients from March 2014 and August 2017, we found that 2 patients positive with adrq ${ }^{+}$ strains developed HCC. Both of our adw2 infected patients had died: one patient from HCC and another patient by LC. (Table 2)

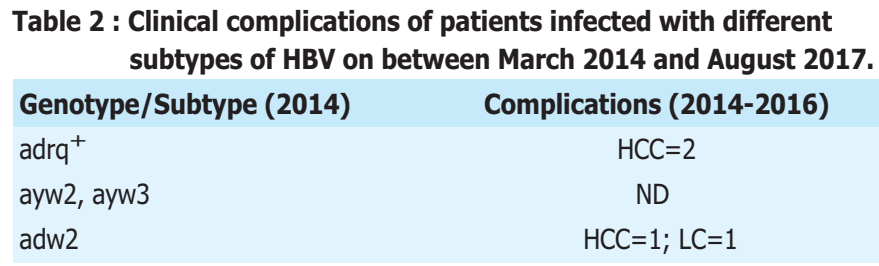

Note : HCC : Hepatocellular Carcinoma; ND: not detectable; LC : Liver Cirrhosis

\section{Discussion}

The extent of HBV replication among chronic hepatitis B patients is very high, about more than $10^{8}$ to $10^{11}$ viral particles per day. ${ }^{24}$ As RT of Pol has no proof reading capacity, HBV replication is also associated with a high mutational rate of $10^{5}$ substitutions/base/cycle. ${ }^{25}$ Therefore, all possible single base changes in the HBV genome are generated daily, therefore many genotypes and subtypes of HBV and also different type of genomic mutations emerge.

As the distribution of subtypes of HBV in our country is very little known, thus we demand it for search. Therefore, this study will support to develop appropriate vaccine for Bangladeshi population.

Our present study showed that most prevalent HBV subtypes were $\mathrm{adrq}^{+}$followed by ayw3 (8/27.6\%). Whereas, adw2 $(2 / 6.9 \%)$ and ayw2 (2/6.9\%) were less dominant subtypes. Former study by Rahman et al also showed that the prevalent HBV subtypes were adr (41\%), followed by adw2 (28.2\%) and ayw3 (25.6\%), and less dominant was ayw2 (5.1\%) in Bangladesh. ${ }^{26}$

In correlation with genotypes and subtypes, we found all the genotype $\mathrm{C}$ showed subtype adrq ${ }^{+}$and genotype $\mathrm{A}$ had adw2. Whereas, genotype $\mathrm{D}$ belonged to two different subtypes: ayw3 (8/27.6\%) and ayw2(2/6.9\%). This findings was consistent with the previous studies reported from Bangladesh and India. 13,26
One study from Shaha et al showed that subtypes associated with genotype D were ayw3 (64.3\%) and ayw2 (35.7\%), and subtypes adw2 and adr were specific for genotype $A$ and $C$ in Bangladesh respectively. ${ }^{26}$ Whereas, Rahman et al showed that the subtype adr completely restricted on genomic group $\mathrm{C}$, while, the subtype adw2 found within the both genotype A and $C$, and the subtype ayw were mostly found among the genotype D. ${ }^{13}$ In comparison of the geographical distribution of HBV, we found that genotype A (subtypes adw2 and ayw1)is most prevalent in North America and North Western Europe. Genotypes B (subtypes adw2, adw3 and ayw1) and C (subtypes adw2, ayw3, adr and ayr) are highly prevalent in East Asia. Genotype D (subtypes adw3, ayw2, ayw3 and ayw4) is most prevalent in the Mediterranean and the Middle East. Genotype E (subtype ayw4) found in West Africa. Genotypes F (subtypes adw4 and ayw4) and $\mathrm{H}$ (subtype adw4) are found in Central and South America. Genotype G (subtype adw2) is found in the United States and Europe. 12,27

Further observation of the clinical complications on the year of March 2014 to August 2017, we found that HCC developed in 2 patients positive with $\mathrm{adrq}^{+}$strains. Both of the patients infected with adw2 strains had died from the complication of HBV infection: one patient from HCC and another patient by LC. Therefore, we suggested that the patients infected with adw2 and $\mathrm{adrq}^{+}$strains need to be careful monitoring to assess their clinical outcome in future.

\section{Conclusion}

In conclusion of our study, the prevalent Bangladeshi HBV subtype was genotype adrq ${ }^{+}$, this was followed by ayw3, while adw2 and ayw2 were present in limited number of patients. Subtype adw2 and adrq $^{+}$strains are found to be related with more complication, therefore, patients infected with these HBV strains need to be careful monitoring to assess their clinical outcome in future.

\section{Limitations of Study}

The present study conducted with a small sample size, so statistical association could not be done adequately.

\section{Recommendations}

Larger sample size should be required for statistical validity.

\section{Acknowledgments}

We appreciate the excellent technical and scientific assistance of Dr. Mohammad Enayet Hossain, Dr. Safiullah Sarkar, Dr. Tasnim Azim, Razibur Rahman, Rashedul Hassan, Sanjoy Mukharjee, Sadia Ahmed, Farzana Ahmed, Warda Hauque, Subarna Barua and A.M Ramim from the Virology Laboratory, icddr,b, Dhaka, Bangladesh. Special thanks to Dr. Mamun-Al-Mahtab from the Bangabandhu Sheikh Mujib Medical University, Dhaka, 
Bangladesh and Prof. Jalaluddin Ashraful Haq, Prof. Md. Shah Alam and Dr. Masuda Mohsena from Ibrahim Medical College, Dhaka, Bangladesh. My thanks also go to the laboratory technicians and other staffs of the Department of Virology, BSMMU and icddr,b for their co-operation.

\section{Conflict of Interest : No conflict of interest to declare.}

\section{References}

1. WHO - World Health Organization 2014. Hepatitis B. Available from:who.int/.

2. Lu HY, Zeng $Z$, Xu XY, Zhang NL, Yu M, Gong WB, Mutations in surface and polymerase gene of chronic hepatitis-B patients with coexisting $\mathrm{HBsAg}$ and anti-HBs,WJG 2006;12(26); 4219-4223.

3. Al-Mahtab $M$, Rahman $S$, Khan $M$, Kamal $M$, Karim MF, Ahmed $F$, et al., Aetiology of chronic hepatitis in Bangladesh, Indian J Gastroenterol 2007; 26 (2); 142.

4. Rudra S, Chakrabarty P, Poddar B, Prevalence of hepatitis B and hepatitis C virus infection in human of Mymensingh, Bangladesh, MMJ 2011;20; 183186.

5. Ashraf $\mathrm{H}$, Alam NH, Rothermundt $\mathrm{C}$, Brooks A, Bardhan $\mathrm{P}$, Hossain $\mathrm{L}$ et al., Prevalence and risk factors of hepatitis $B$ and $C$ virus infections in an impoverished urban community in Dhaka, Bangladesh, BMC Infect Dis 2010; 10; 208.

6. Yahyapour Y, Karimi M, Molaei HR, Khoddami E, Mahmoudi M, Active-passive Immunization Effectiveness Against Hepatitis B Virus in Children Born to HBsAg Positive Mothers in Amol, North of Iran, OMJ 2011; 26; 399-403.

7. Khan M, Alam MS, Antiviral resistance with lamivudine therapy in chronic hepatitis B, Orion Med J2008; 30; 546.

8. Afroz S, Mahtab MA, Rahman S, Khan M, Hepatitis B virus is the leading cause of cirrhosis of liver in Bangladesh, Hepatol Int 2007; 1 (1); 120.

9. Yousif $M$, Kramvis $A$, Genotype $D$ of hepatitis $B$ virus and its sub genotypes: An update, Hepatol Res2013; 43; 355-364.

10. Santos AO, Alvarado-Mora MV, Botelho L, Vieira DS, Pinho JR, Carrilho FJ et al., Characterization of hepatitis B virus (HBV) genotypes in patients from Rondônia, Brazil,Virol J2010; 7; 315.

11. Kramvis A, Arakawa K, Yu MC, Nogueira R, Stram DO, Kew MC, Relationship of serological subtype, basic core promoter and precore mutations to genotypes/subgenotypes of hepatitis B virus, J Med Virol2008; 80; 27-46.
12. Norder H, Couroucé A, Coursaget $P$, Echevarria J et al., Genetic Diversity of Hepatitis B Virus Strains Derived Worldwide: Genotypes, Subgenotypes and $H B<$ sub $>$ s $</$ sub $>A g$ Subtypes, Intervirol 2004; 47; 289-309.

13. Rahman MA, Hakim F, Ahmed M, Ahsan CR, Nessa J, Yasmin M, Prevalence of genotypes and subtypes of hepatitis B viruses in Bangladeshi population, Spring Plus 2016; 5; 278.

14. HPA Document Control System, VW-0461.01, 2007.

15. Hall T, Bio Edit: A user-friendly biological sequence alignment editor and analysis program for Windows 95/98/NT, Nucleic Acids Symp Ser 1999; 41; 95-98.

16. Tamura K, Stecher G, Peterson D, Filipski A, Kumar S, MEGA6: Molecular Evolutionary Genetics Analysis version 6.0,J Mol Biol Evol 2013; 30; 27252729.

17. Felsenstein J, Confidence limits on phylogenies: An approach using the bootstrap. Evol 1985; 39; 783-791.

18. Nei M, Kumar, S, Molecular Evolution and Phylogenetics. Oxford University Press, New York 2000.

19. HIV-grade HBV drug resistance interpretation. Available from; URL: http://www.hiv-grade.d e/hbv_grade/deployed/grade.pl?program=hbvalg.

20. The Genafor/Arevir geno2pheno drug resistance tool. Center of Advanced European Studies and Research, Bonn, Germany. Available from; URL: http://coreceptor.bioinf.mpi-inf.mpg.de.

21. HEPSEQ Polymerase annotator tool. Available from; URL: http://www. hepseq.Org/Public/Tool/annotator_tool.php.

22. Lazarevic, Clinical implications of hepatitis B virus mutations: Recent Advances,WJG2014; 20(24); 7653-7664.

23. Moradi A, Zhand S, Ghaemi A, Javid N, Tabarraei A, Mutations in the $S$ gene region of hepatitis $B$ virus genotype $D$ in Golestan Province-Iran,Virus Genes 2012; 44(3); 382-7.

24. Coleman PF, Detecting hepatitis B surface antigen mutants, Emerg Infec Dis 2006; 12; 198-203.

25. Locarnini $S$, Clinical relevance of viral dynamics and genotypes in hepatitis $B$ virus, JGH 2002;17(3); S322-8.

26. Shaha, M, Hoque SA, Rahman SR, Molecular epidemiology of hepatitis B virus isolated from Bangladesh, Spring Plus 2016; 5.1; 1-7.

27. Ong HT, Duraisamy G, Kee Peng N, Wen Siang T, Seow HF, Genotyping of hepatitis $B$ virus in Malaysia based on the nucleotide sequence of pre $S$ and $S$ genes, Microb Infec 2005;7(3); 494-500. 